Relations industrielles

Industrial Relations

\title{
Industry and Social Life, Edward Gross, Wm. C. Brown Company Publishers, Iowa, 1965, 172 pages.
}

\section{Ronald Pleau}

Volume 21, numéro 1, 1966

URI : https://id.erudit.org/iderudit/027666ar

DOI : https://doi.org/10.7202/027666ar

Aller au sommaire du numéro

Éditeur(s)

Département des relations industrielles de l'Université Laval

ISSN

0034-379X (imprimé)

1703-8138 (numérique)

Découvrir la revue

Citer ce compte rendu

Pleau, R. (1966). Compte rendu de [Industry and Social Life, Edward Gross, Wm. C. Brown Company Publishers, Iowa, 1965, 172 pages.] Relations industrielles / Industrial Relations, 21(1), 112-112. https://doi.org/10.7202/027666ar

Tous droits réservés (C Département des relations industrielles de l'Université Laval, 1966
Ce document est protégé par la loi sur le droit d'auteur. L'utilisation des services d'Érudit (y compris la reproduction) est assujettie à sa politique d'utilisation que vous pouvez consulter en ligne.

https://apropos.erudit.org/fr/usagers/politique-dutilisation/ 
les différents problèmes de comportement que l'on rencontrera dans les structures d'organisation qu'elles soient militaires, sociales, gouvernementoles ou industrielles.

\section{Ronald Pleau}

Industry and Social Life, Edward Gross, Wm. C. Brown Company Publishers, lowa, 1965, 172 pages.

Nous savons que l'industrialisation est un phénomène qui a eu des effets considérables sur nos sociétés. Aussi pour que ces dernières ne se laissent pas submerger par les changements et les transformations, il faut que les chercheurs de différentes disciplines analysent les nombreux aspects du phénomène et dégagent les ajustements sociaux nécessaires. II s'agit donc pour eux de concilier la technologie avec les systèmes sociaux, les structures et les organisations sociales.

Ceci ne s'effectuera que si nous connaissons bien les relations entre l'industrialisation et la socialisation.

Le contenu de ce volume consiste donc en une synthèse comparative et critique qui exomine les contributions de la sociologie ò la nouvelle discipline des relations industrielles. II nous présente une nouvelle forme de pensée eu égard à la relation qui existe entre ces deux champs d'études.

Les recherches rapportées dans cet ouvrage sont présentées dans le contexte même des principoux sujets des relations industrielles à savoir le trovail et les loisirs, l'aliénation, la légitimation du pouvoir de la direction, les coûts de l'organisation en termes humains.

Divisée en huit chapitres relativement courts cette étude nous donne l'occasion de passer en revue des principes fondamentoux des relations de travail, les droits de la direction, la structure morale du trovail, la relation de l'industrie avec la communauté environnante.

Dans une section subséquente, il est question de la direction. On discute ici des problèmes du leadership dans l'organisation, de la surveillance, des relations et de la succession de la direction.

Puis Gross passe ò l'étude de l'organisotion industrielle comme tout, i.e. des types d'organisation et des systèmes de contrôle du travail. Et avant de traiter des relations informelles à l'intérieur des groupes de travail et entre les professionnels dans l'industrie (chap. 6) il nous présente quelques aspects relatifs aux carrières tels la mobilité du travail, la sélection et l'importance de la personnalité dans l'industrie.

Enfin, ce sont les syndicats ouvriers comme mouvements sociaux dans leurs relations avec les autres composantes de l'industrie qui font l'objet d'une discussion.

Le tout se termine sur une note psycholooique avec l'élaboration de questions toujours d'actualité telles la satisfaction et la motivation au travail, les systèmes de stimulants et l'efficacité au travail.

Il ne faudrait pas omettre de mentionner l'excellente liste de références (environ 350) qui vient ajouter un élément de plus à la valeur de ce document lequel constitue, à mon sens, une excellente contribution à la compréhension des relations industrielles et en particulier de la sociologie industrielle.

\section{Ronald Pleau}

Readings in Labord Economics, Edited by Gordon F. Bloom, Herbert R. Northrup and Richard L. Rowan, Richard D. Irwin, Inc., Illinois, 1963. 707 pages.

Ce volume, conçu pour accommoder les étudiants qui suivent des cours dans le domaine des relations de travail et de l'économique du travail, présente une cinquantaine d'articles d'auteurs bien connus: Dunlop, Perlman, Kerr, Barbosh... De plus ces textes furent choisis parce qu'ils pouvaient compléter les textes de base sur le sujet.

Présentant d'abord quelques articles d'introduction sur la société industrielle et la force de travail, on traite ensuite de différents aspects de I'histoire du syndicalisme américain : un cadre théorique sur son développement, les Chevaliers du Travail, la victoire du syndicalisme de métier, les I.W.W. et l'époque du « New Deol ».

La troisième partie aborde certains problèmes de la structure et du gouvernement des syndicats américains: les changements structurels de ces syndicats et leur influence sur le système de relations industrielles, la gestion financière et la démocratie à l'intérieur des grandes organisations syndicales. Ces sujets donnent des réponses c̀ certaines questions. Quels sont les principaux changements qui ont influencé le système de la négociation collective? Quelle est la stabilité du syndicalisme américain? Comment les cotisations syndicales sont-elles em- 